\title{
Suitability of pesticide risk indicators for less developed countries: a comparison
}

Article

Accepted Version

Feola, G., Rahn, E. and Binder, C.R. (2011) Suitability of pesticide risk indicators for less developed countries: a comparison. Agriculture, Ecosystems and Environment, 142 (3-4). pp. 238-245. ISSN 0167-8809 doi:

https://doi.org/10.1016/j.agee.2011.05.014 Available at https://centaur.reading.ac.uk/23998/

It is advisable to refer to the publisher's version if you intend to cite from the work. See Guidance on citing.

To link to this article DOI: http://dx.doi.org/10.1016/j.agee.2011.05.014

Publisher: Elsevier

All outputs in CentAUR are protected by Intellectual Property Rights law, including copyright law. Copyright and IPR is retained by the creators or other copyright holders. Terms and conditions for use of this material are defined in the End User Agreement.

\section{www.reading.ac.uk/centaur}

\section{CentAUR}

Central Archive at the University of Reading 
Reading's research outputs online 


\title{
1Suitability of pesticide risk indicators for less developed countries: a comparison
}

2Feola, G. ${ }^{1,2^{*}}$, Rahn, E. ${ }^{1,3}$, Binder, C.R. ${ }^{1,4}$

\author{
$4^{1}$ Department of Geography, University of Zurich, Winterthurerstrasse 190, 8057 Zurich, Switzerland \\ $5^{2}$ Potsdam Institute for Climate Impact Research, Telegraphenberg A62, 14473 Potsdam, Germany \\ $6^{3}$ Federal Office for Spatial Development, Mühlestrasse 2, CH-3063 Ittigen, Switzerland \\ $7^{4}$ Institute for System Science, Innovation and Sustainability Research, University of Graz, Merangasse 18/I, \\ 88010 Graz, Austria \\ 9* Corresponding author: feola.giuseppe@googlemail.com
}

10

11

\section{Abstract}

13Pesticide risk indicators provide simple support in the assessment of environmental and health 14risks from pesticide use, and can therefore inform policies to foster a sustainable interaction of 15agriculture with the environment. For their relative simplicity, indicators may be particularly 16useful under conditions of limited data availability and resources, such as in Less Developed 17Countries (LDC). However, indicator complexity can vary significantly, in particular between 18those that rely on an exposure-toxicity ratio (ETR) and those that do not. In addition, pesticide 19risk indicators are usually developed for Western contexts, which might cause incorrect 20estimation in LDCs. This study investigated the appropriateness of seven pesticide risk 21 indicators for use in LDCs, with reference to smallholding agriculture in Colombia. Seven 22farm-level indicators, among which 3 relied on an ETR (POCER, EPRIP, PIRI) and 4 on a 23non-ETR approach (EIQ, PestScreen, OHRI, Dosemeci et al., 2002), were calculated and then 24compared by means of the Spearman rank correlation test. Indicators were also compared 25 with respect to key indicator characteristics, i.e. user friendliness and ability to represent the 26system under study. The comparison of the indicators in terms of the total environmental risk 
1suggests that the indicators not relying on an ETR approach cannot be used as a reliable proxy 2 for more complex, i.e. ETR, indicators. ETR indicators, when user-friendly, show a 3 comparative advantage over non-ETR in best combining the need for a relatively simple tool 4to be used in contexts of limited data availability and resources, and for a reliable estimation 5of environmental risk. Non-ETR indicators remain useful and accessible tools to discriminate 6between different pesticides prior to application. Concerning the human health risk, simple 7algorithms seem more appropriate for assessing human health risk in LDCs. However, further 8research on health risk indicators and their validation under LDC conditions is needed.

9

\section{Keywords}

11Pesticide use, environmental risk, occupational health risk, assessment, indicator, Colombia 12

\section{Introduction}

14Pesticide risk indicators can support the assessment of environmental and health risks from 15pesticide use. They can be utilized by different kinds of users, such as farmers, extension 16agents, policy-makers, regulatory agencies and academia (Levitan, 2000). They serve as a 17basis for the evaluation of different pest management strategies (Levitan, 2000; Greitens and 18Day, 2007), and for the development, monitoring and assessment of environmental and health 19policies (Levitan, 2000; Maud et al., 2001; Falconer, 2002; Finizio and Villa, 2002). Thus, 20pesticide risk indicators can signal risky agricultural practices and inform interventions and 21policies to foster a sustainable interaction of agriculture with the environment on which 22agriculture itself relies. The contribution of pesticide risk indicators, and more in general of 23sustainability indicators, in helping minimising the impact of agriculture on the environment 24has been recognized not only in academia, but in the policy arena, which has often taken a 
1proactive role in stimulating research on sustainability indicators in agriculture (e.g. CEC, 21999; OECD 1999 and 2001).

3Simplicity is a generally acknowledged feature of indicators. This often makes them 4acceptable, usable even with scarce data, quick to calculate and easy to communicate, 5although at the expense of a more realistic representation of pesticide impacts (van der Werf, 61996; Castoldi et al., 2007). In this regard, indicator-based assessment methods gain a 7comparative advantage over alternative assessment systems, such as direct measurements or 8simulation modelling, which instead require more qualified expertise, economic resources and 9data which might not always be available.

10However, the level of complexity of pesticide risk indicators can also vary significantly. Two 11 broad typologies of indicators can be identified (Reus et al., 2002). The first includes user 12 friendly assessment tools, usually with few input data requirements, and a scoring table based 13on rather simple algorithms which are often constructed on the basis of expert judgment. 14These indicators usually score pesticide properties first, which are then multiplied by the 15application rate. Finally, the scores are aggregated by summation. The second typology 16includes indicators using a risk-ratio, or exposure-toxicity ratio (ETR) approach, i.e. "the ratio 17between exposure (usually the concentration in a certain environmental compartment) and 18toxicity for relevant organisms" (Reus et al., 2002). These indicators are considered to better 19represent and quantify environmental risks from pesticide use, but have the drawbacks of 20requiring more detailed input data and the support of computer modelling (Reus et al., 2002; 21Castoldi et al., 2007). These indicators use the application rate to calculate pesticide 22 concentrations, which are then scored by environmental compartment. The compartment 23 scores can then be integrated by summation or by multiplication. Thus, from a mathematical 24perspective, the most significant difference between ETR and non-ETR indicators is how the 25application rate is included in the risk estimation. 
1The extent to which simple and complex pesticide risk indicators provide convergent 2assessment results is an open issue. Convergent results would allow for considering simple 3indicators as proxy to the more complex ones, and therefore allow them to be used as easy-to4use diagnostic tools. However, previous comparative studies highlighted a divergence rather 5than a convergence in assessment results (e.g. Maud et al., 2001; Reus et al., 2002).

6The quest for simple but reliable assessment methods is particularly relevant in Less 7Developed Countries (LDC). In effect, not only are LDCs often characterised by particularly 8serious pesticide-related externalities (e.g. Pimentel et al., 1992; Ecobichon, 2001), but also 9by a general limited ability in environmental and agricultural research and monitoring. The 10latter can be in broad terms related to two issues, i.e. lack of skilled human resources, with 11 brain drain and de-qualification affecting many countries (UNESCO, 2009), and lack of 12 infrastructure (e.g. information technology, laboratories) and financial resources to access and 13produce reliable data and information (Zhen and Routray, 2003; UNESCO, 2009).

14Furthermore, one open issue is that pesticide risk indicators are usually developed for 15productive and pedoclimatic conditions in Western countries, which might imply, especially 16for indicators relying on expert judgement, an incorrect assessment of pesticide risks in LDCs. 17Pesticide risk indicators have been used in LDCs, but usually with a preference for simple, 18non-ETR types (e.g. Muhammetoglu and Uslu, 2007; Pradel et al., 2009), an exception being 19a study of Kookana et al. (2007). However, while comparative evaluations of pesticide risk 20indicators exist (e.g. Maud et al., 2001; Reus et al., 2002; Stenrod et al., 2008), they do not 21refer to the conditions of resource availability usually encountered in LDCs. Moreover, 22comparative evaluations of indicators have neglected human health risk indicators. Analysing 23also this kind of indicators is of fundamental importance in LDCs, because pesticide 24application practices often differ significantly from those adopted in Western countries 25(Matthews, 2008). Such differences in contextual factors, in particular pesticide application 
1techniques, suggest that the applicability of health risk indicators in LDCs might be limited, 2and call for the need for contextualizing pesticide risk, e.g. to understand the determinants of 3exposure more than to quantify levels of risk (Blanco et al., 2005).

4Consequently, it is not clear what indicators might be more appropriate to assess 5environmental and health risks from pesticide use, and thus properly inform agricultural 6management, under pesticide application practices typical of LDCs. The objective of this 7study was to investigate the appropriateness of seven pesticide risk indicators for use at farm 8level in LDCs, with particular reference to smallholding agriculture in the Colombian Andean 9region. With reference to this area, two research questions drove the study:

10 i) Can simple pesticide risk indicators be used as proxies for more complex ones, 11 thus facilitating the task of risk assessment?

12 ii) What is the most appropriate indicator to assess pesticide risk to human health and 13 the environment?

14The paper is structured as follows. Firstly, a short description of the indicators selected, study 15area, data used and comparative procedure adopted are provided. Secondly, the results are 16presented separately for environmental and human health risk indicators. Finally, results are 17 discussed with reference to the two research questions, and conclusions on the use of pesticide 18risk indicators in the context of LDCs are drawn.

19

20

21

22

\section{Method}

\subsection{Indicators}


1Seven farm-level indicators (i.e. EIQ, PestScreen, EPRIP, PIRI, POCER, OHRI and the 2indicator proposed by Dosemeci et al., 2002) were selected so that i) every environmental and 3health compartment was considered by at least two of the selected indicators and ii) both 4simple, i.e. non-ETR, and complex, i.e. ETR, indicators were represented (Table 1).

\subsubsection{Coverage of environmental and health compartments}

6Three indicators, i.e. PestScreen (Juraske et al., 2007), EPRIP (Padovani et al., 2004; Trevisan 7et al., 2009), and PIRI (Kookana et al., 2005), focus exclusively on environmental risks, 8 whereby risk to consumer health is implicitly and partly included, since drinking water 9 contamination and ingestion of contaminated food are part of the environmental risk 10assessment. Two indicators, i.e. OHRI (Bergkvist, 2004) and the indicator developed by 11Dosemeci et al. (2002), focus solely on occupational health risk, whereby only the pesticide 12operator is considered. The remaining two indicators, i.e. EIQ (Kovach et al., 1992) and 13POCER (Vercruysse and Steurbaut, 2002), include an environmental risk component and an 14occupational health risk component, whereby both assess the risk to agricultural workers in 15addition to pesticide operators and POCER also considers bystanders' risk to pesticide 16exposure (a short description of the indicators is given in the supplementary data files).

\subsubsection{Representation of ETR and non-ETR indicators}

18Four indicators were chosen that do not rely on an ETR approach, i.e. they transform 19variables into scores which, in turn, are aggregated empirically (EIQ, PestScreen, OHRI and 20the indicator from Dosemeci et al., 2002), and three indicators were chosen which rely on the 21ETR approach (POCER, EPRIP, PIRI). The first four indicators are considered simple 22 indicators because they do not make use of site specific data (e.g. pedoclimatic conditions) 23 and because pre-calculated hazard scores are multiplied with application rates by the end-user, 24 which results in low data requirements. The latter three indicators take into account site 25 specific data, make use of the ETR approach and are more data demanding. 


\subsubsection{Further indicator characteristics}

2PestScreen, POCER, EPRIP and PIRI all implement at least some of the suggestions made in 3earlier studies for the development of more accurate pesticide risk indicators (Levitan, 1997 4and 2000; Maud et al., 2001; Reus et al., 2002). Among these suggestions were: to be 5analogous to the technical concept of risk, to have large potential ranges to allow for 6differentiation between pesticides, to include application rate, application factors and 7environmental conditions, to give separate rankings for different compartments (including 8human health). On the other hand, EIQ is one of the most dated, but also one of the most 9widely used indicators, with numerous applications in LDCs (e.g. Muhammetoglu and Uslu, 102007; Pradel et al., 2009).

11Finally, all indicators chosen present a relative outcome. That is, instead of providing an 12absolute value, the assessment provides a qualitative statement on the relative risks a pesticide 13application or control strategy might have in comparison to the application of another 14pesticide or to a control strategy based on different pesticides.

16Table 1. Risk indicators considered in this study by environmental and health compartments

\begin{tabular}{|c|c|c|c|c|c|c|c|c|c|c|}
\hline \multirow[b]{2}{*}{ Indicator } & \multicolumn{5}{|c|}{ Environment } & \multicolumn{3}{|c|}{ Health } & \multicolumn{2}{|c|}{ Calculation methodology } \\
\hline & Soil & Air & $\begin{array}{c}\text { Surface } \\
\text { water }\end{array}$ & Groundwater & $\begin{array}{r}\text { Beneficial } \\
\text { arthropods }\end{array}$ & $\begin{array}{l}\text { Pesticide } \\
\text { operator }\end{array}$ & Farm worker & Consumer & ETR & Non-ETR \\
\hline EIQ & & & $*$ & $*$ & $*$ & $*$ & $*$ & $*$ & & $*$ \\
\hline PestScreen & * & * & $*$ & $*$ & & & & $*$ & & $*$ \\
\hline POCER & $*$ & & $*$ & $*$ & * & * & * & $*$ & * & \\
\hline EPRIP & $*$ & * & $*$ & $*$ & & & & $*$ & $*$ & \\
\hline PIRI & & & $*$ & $*$ & & & & $*$ & $*$ & \\
\hline OHRI & & & & & & $*$ & & & & $*$ \\
\hline Dosemeci et al. (2002) & & & & & & $*$ & & & & $*$ \\
\hline
\end{tabular}

18

192.2. Data

202.2.1. Data and study area 
1The data necessary to calculate the indicator rankings were mainly derived from an existing 2 georeferenced dataset produced in a previous study in the vereda (community) called La 3Hoya, located in the Department of Boyacá, in the eastern chain of the Colombian Andes 4(Feola, 2010a). For many aspects such as pesticide application technique or socio5demographic structure, this study area may be considered typical of the broader Andean 6region (Feola, 2010a) and very similar to other rural areas in LDCs (Matthews, 2008).

7Vereda La Hoya ranges from 2,700 to 3,250 masl over an area of $8.4 \mathrm{~km}^{2}$ ( $840 \mathrm{ha}$ ), and has a 8population of about 750 inhabitants. It is a rural region mainly dedicated to the cultivation of 9potato (MADR, 2006). The production of potato in Vereda La Hoya relies mainly on 10smallholders, who cultivate an average of 3 hectares subdivided into different plots. The land 11 is cultivated in two cycles a year (September to February and March to August). Average 12productivity rates range between 15 and 17 ton/ha (MADR, 2006). Potato crops in this region 13are vulnerable to three major pests: the soil-dwelling larvae of the Andean weevil 14(Premnotrypes vorax), the late blight fungus (Phytophthora infestans) and the Guatemalan 15 potato moth (Tecia solanivora) . To protect the crop from these pests, the use of chemical 16pesticides, in particular insecticides and fungicides, is widespread among smallholders (Feola 17and Binder, 2010b). The most common way of applying pesticide is by means of a lever18operated knapsack sprayer (20-25 litres), which is filled from a bigger tank, usually of about 19200 litres, where the pesticide mix is prepared.

20Also as a result of the misuse of personal protective equipment (PPE), high levels of 21pesticide-related health risk have been observed in the region (Cardenas et al., 2005; Ospina 22et al., 2008; Feola, 2010b). Regarding adverse environmental effects, both Schoell and 23Binder (2009) and Feola and Binder (2010b) reported that farmers in Vereda La Hoya 24observed a pesticide-related reduction of soil biodiversity in recent years. Finally, pesticide 25overuse has attracted the concern of governmental agencies because of its economic 
1 drawbacks (MADR, 2004). In this respect, Feola and Binder (2010b), showed that some of 2the farmers tend to use pesticides ineffectively, with a persistent overuse.

3The data used in this study to calculate the indicator values were gathered through a survey 4carried out in La Hoya in 2007 (Feola and Binder, 2010c). The data consisted of detailed 5information on 72 farmers' safety practices (e.g. hygiene and use of personal protective 6equipment) and pesticide applications on one selected plot. The reference period for the data 7was one entire agricultural cycle (March to August 2007).

8

\subsubsection{Additional data}

10Additional data necessary to calculate the indicators was gathered from various sources. 11Pesticide properties were obtained through the Pesticide Properties Database (PPDB, 2009). 12Climatic data, such as precipitation and temperature (for the years 1994-2003), were obtained 13 from the Instituto de Hidrologia, Meteorologia y Estudios Ambientales de Colombia. For the 14reference period the temperature was between an average minimum of $5.7^{\circ} \mathrm{C}$ and an average 15 maximum of $20^{\circ} \mathrm{C}$. Total annual precipitation in the reference period was $343.5 \mathrm{~mm}$. For soil 16parameters, the classification of "clay loam" was used (Binder and Patzel, 2001). According 17 to Leuenberger (2005) average organic carbon content in the study area was $6.4 \%$. Mean bulk 18density was assumed to be 0.9 tons per $\mathrm{m}^{3}$ according to Binder and Patzel (2001). Soil loss 19was adapted from Binder and Patzel (2001) and assumed to be 9.6 tons per hectare and year. 20The distance of the plot to water bodies was calculated with the software ESRI ArcGIS 9.3. 21An overview of the data used to calculate the indicators is available in the supplementary data 22files.

\subsection{Procedure}


1The study consisted of three phases. First, the indicator values were calculated for the pest 2control strategy and for single pesticide applications. A pest control strategy is defined for 3each of the 72 farmers as the total amount of pesticide applied by active ingredient (examples 4of pesticide application patterns and strategies can be found in Feola and Binder, 2010b, and 5Juraske et al., 2011). For EIQ and EPRIP, the number, frequency and sequence of applications 6also contributes in differentiating among pest control strategies, since they propose how to 7 calculate the cumulative risk which occurs when several applications of different active 8ingredients are used within the same pest control strategy. Concerning the single pesticide 9applications, the 72 farmers applied pesticides a total of 1772 times to their fields during the 10agricultural cycle considered. These applications were aggregated by summing up all 11 applications of a particular pesticide during each of the five production phases (i.e. sowing of 12the potato, emergence of the shoot, weeding, earthing up, and maintenance). For example, if a 13farmer applied carbofuran four times with varying application rates during the emergence of 14the potato shoot, the indicator values were calculated for all four applications taken together. 15Accordingly, the amount of applications analysed decreased to 581. In sum, 72 pest control 16strategies, i.e. each strategy consisting of all applications for each single farmer, and 581 17pesticide applications, were considered.

18Second, the indicator rankings were compared by means of the Spearman rank correlation 19test, in accordance with Maud et al. (2001) and Reus et al. (2002), and using the software 20PASW Statistics 18.0. Not only were the indicators compared with respect to their overall 21outcome (Figure 1, quadrant 1), but also every individual environmental and health risk 22component that the indicators have in common (Table 1) was compared separately (Figure 1, 23quadrant 2). Furthermore, the indicators were compared with regard to both the 518 pesticide 24applications and the 72 control strategies (Figure 1, quadrants 3 and 4). Since only EIQ and 25EPRIP propose how to calculate the cumulative risk accruing when several applications of 26different active ingredients are used within the same pest control strategy, the other indicator's 1Agriculture, Ecosystems and Environment 142 (2011) 238-245, DOI: 10.1016/j.agee.2011.05.014 
1values for the pest control strategies were simply summed up from those of the single 2applications, as proposed by Kovach (1992). Due to the lack of daily meteorological data, the 3groundwater module of POCER was not calculated through the suggested PESTLA model, 4but through the groundwater module of the PIRI indicator. PestScreen, which does not 5propose rankings for single environmental compartments, was compared to other indicators 6only with respect to the total environmental risk. In addition, the comparison was carried out 7separately for environmental and occupational health indicators (Figure 1).

8Third, a comparison based on key indicator characteristics was made, taking into account each 9indicator's user friendliness (i.e. data availability, calculation procedure, and interpretation of 10ranking) and ability to represent the specific system under study (i.e. compartments 11 considered, use of site specific data). The former refers to the procedural dimension of 12sustainability assessment (Binder et al., 2010), and concerns the indicator best suited to 13practical use in LDCs. The latter refers to the systemic dimension of sustainability assessment 14(Binder et al., 2010), and entails the coverage of all relevant ecosystem and human system 15(i.e. health) compartments. This also entails the use of site specific information, which might 16significantly alter the estimated level of risk associated with a given application of pesticide 17due to, for instance, the influence of environmental characteristics such as soil composition on 18the persistence of active components in the ecosystem under study (the details of the criteria 19used for this comparison are given in the supplementary data files). 


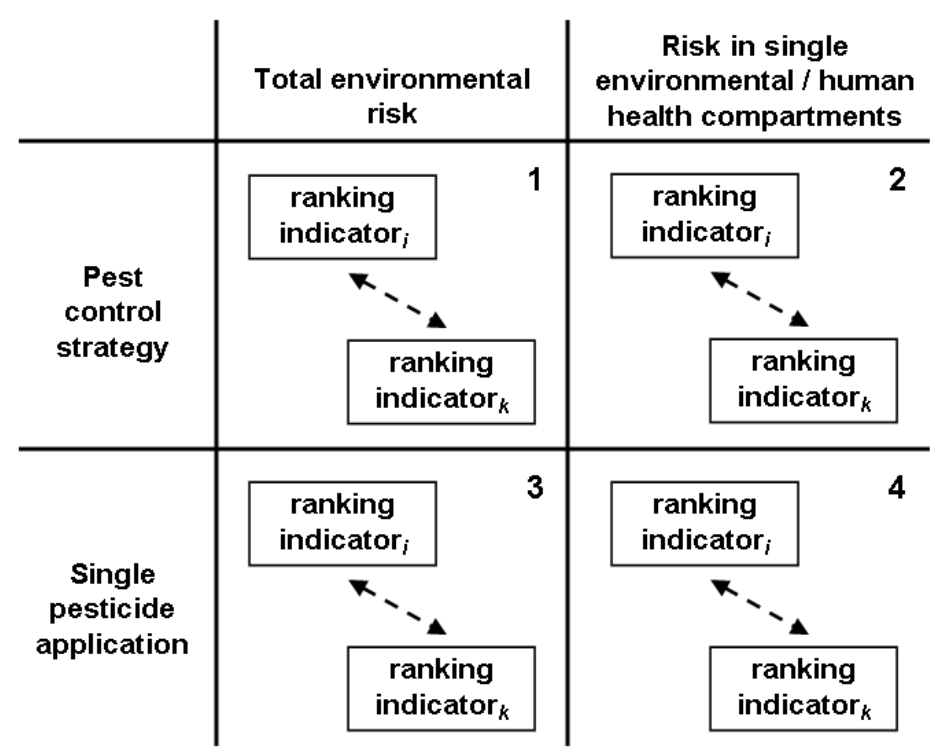

1

2Figure 1. Comparative analysis of the indicator rankings. The subscripts $i$ and $k$ indicate indicators 3among the ones compared in the study.

4

\section{Results}

\subsection{Comparison of indicators based on rankings: environmental risk}

\subsubsection{Total environmental risk}

8Four indicators aggregate the risk to the different environmental compartments into an overall 9risk value, namely EIQ, PestScreen, POCER and EPRIP. The highest and significant 10correlations between rankings were those between EIQ and PestScreen (both non-ETR) and 11between POCER and EPRIP (both ETR). The latter decreased when control strategy instead 12of single applications was considered, while all other correlations increased. EIQ and 13PestScreen showed a high correlation with the application rate (Table 2). 
1Table 2. Correlation between rankings of the 581 pesticide applications, and between rankings of the 72 2 control strategies (in italics) for total environmental risk (Spearman correlation test)

\begin{tabular}{|c|c|c|c|c|c|}
\hline & EIQ & PestScreen & POCER & EPRIP & Application rate \\
\hline$\overline{\mathrm{EIQ}}$ & 1.00 & & & & \\
\hline PestScreen & $0.96 * *$ & 1.00 & & & \\
\hline POCER & $-0.08 *$ & $-0.18 * *$ & 1.00 & & \\
\hline EPRIP & $0.12 * *$ & 0.02 & $0.74 * *$ & 1.00 & \\
\hline Application rate & $0.96 * *$ & $0.98 * *$ & $-0.27 * *$ & -0.03 & 1.00 \\
\hline
\end{tabular}

4

\subsubsection{Risk to surface water and groundwater}

6Four indicators rank the risk to surface water, namely EIQ, POCER, EPRIP and PIRI, while 7three of these, i.e. EIQ, EPRIP and PIRI, also rank the risk to groundwater. The rankings for 8all indicators correlated with each other, albeit with differing strength. Regarding the risk to 9surface water, EPRIP was the only indicator for which the correlation with the other 10indicators was smaller when the control strategy rather than the single applications was 11 considered, while, for the risk to groundwater, this also occurred for PIRI. EIQ, POCER and 12PIRI had significant correlations with the application rate. In general, correlations between 13rankings of the latter (i.e. POCER, EPRIP, PIRI) tended to be higher than those between 14rankings of ETR and non-ETR indicators (i.e. EIQ) (Tables 3 and 4).

16Table 3. Correlation between rankings of the 581 pesticide applications, and between rankings of the 72 17 control strategies (in italics), for risk to surface water (Spearman correlation test)

\begin{tabular}{|c|c|c|c|c|c|}
\hline & EIQ & PestScreen & POCER & EPRIP & Application rate \\
\hline EIQ & 1.00 & & & & \\
\hline PestScreen & $0.99 * *$ & 1.00 & & & \\
\hline POCER & 0.18 & 0.18 & 1.00 & & \\
\hline EPRIP & 0.05 & 0.05 & $0.34 * *$ & 1.00 & \\
\hline Application rate & $0.98 * *$ & $0.98 * *$ & 0.12 & 0.01 & 1.00 \\
\hline
\end{tabular}


1Table 4. Correlation between rankings of the 581 pesticide applications, and between rankings of the 72 2 control strategies (in italics), for risk to groundwater (Spearman correlation test)

\begin{tabular}{lccccc}
\hline & EIQ & POCER & EPRIP & PIRI & Application rate \\
\hline EIQ & 1.00 & & & & \\
POCER & $0.45^{* *}$ & 1.00 & & & \\
EPRIP & $0.18^{* *}$ & $0.74 * *$ & 1.00 & 1.00 & \\
PIRI & $0.40^{* *}$ & $0.64 * *$ & $0.43 * *$ & $0.33 * *$ & 1.00 \\
\hline
\end{tabular}

4

\subsubsection{Risk to soil and beneficial arthropods, birds and bees}

6Two indicators, namely POCER and EPRIP (both ETR), rank the risk to soil. They correlated 7significantly at 0.01 level (Spearman correlation test 0.82 ); POCER also correlated 8significantly with the application rate (Spearman correlation test 0.42 ).

9The risks to beneficial arthropods, birds and bees are each ranked by EIQ and POCER. 10Significant correlations (at 0.01 level) between the two rankings were observed for the risk to 11 birds, both when single applications and control strategy are considered (Spearman 12correlation test 0.43 and 0.35 respectively). Regarding the risk to bees, the two rankings 13 correlated significantly (at 0.01 level) only when the control strategy was considered 14(Spearman correlation test 0.43 ). Concerning risk to beneficial arthropods, the two rankings 15were significantly, but negatively, correlated (Spearman correlation test -0.5 ) when single 16applications were considered. Finally, for all three compartments, and for both control 17 strategy and single applications, EIQ always correlated significantly at 0.01 level and very 18strongly (Spearman correlation tests $>0.94$ ) with the application rate (Tables showing the 19correlations for these three compartments are given in the supplementary data files). 


\subsection{Comparison of indicators based on rankings: health risk}

2Four indicators rank the risk to the pesticide operator, namely EIQ, POCER, OHRI and the 3indicator from Dosemeci et al. (2002). The latter only provides an assessment of the control 4strategy. When single applications were considered, all rankings correlated with each other 5significantly (Table 5). Both EIQ and POCER also correlated significantly with the 6application rate, while OHRI does not include the application rate in its algorithm. However, 7the rankings correlated less strongly, and in some cases not significantly, when the control 8strategy was considered (Table 5). The highest correlations were observed between EIQ and 9POCER, both of which also significantly and strongly correlate with the application rate 10(Table 5).

11

12Table 5. Correlation between rankings of the 581 pesticide applications, and between rankings of the 72 13 control strategies (in italics), for risk to pesticide operator (Spearman correlation test)

\begin{tabular}{lccccc}
\hline & EIQ & POCER & EPRIP & PIRI & Application rate \\
\hline EIQ & 1.00 & & & & \\
POCER & $0.51 * *$ & 1.00 & & & \\
EPRIP & 0.13 & $0.61 * *$ & 1.00 & 1.00 & \\
PIRI & $0.58 * *$ & $0.70 * *$ & $0.31 * *$ & $0.49 * *$ & 1.00 \\
\hline
\end{tabular}

15

16Two indicators rank the risk for farm workers, namely EIQ and POCER. The two rankings 17correlated significantly at the 0.01 level and rather strongly, considering both single 18applications and control strategies (Spearman correlation tests 0.56 and 0.49 respectively). 19Both indicators correlated significantly with the application rate (Table given in the 20supplementary data).

21 


\subsection{Comparison of indicators based on key indicator characteristics}

2The results of the comparison based on key indicator characteristics are shown in Table 6 (the 3 details of the criteria used for this comparison are given in the supplementary data files).

4

5Table 6. Comparison based on key indicator characteristics of the selected indicators.

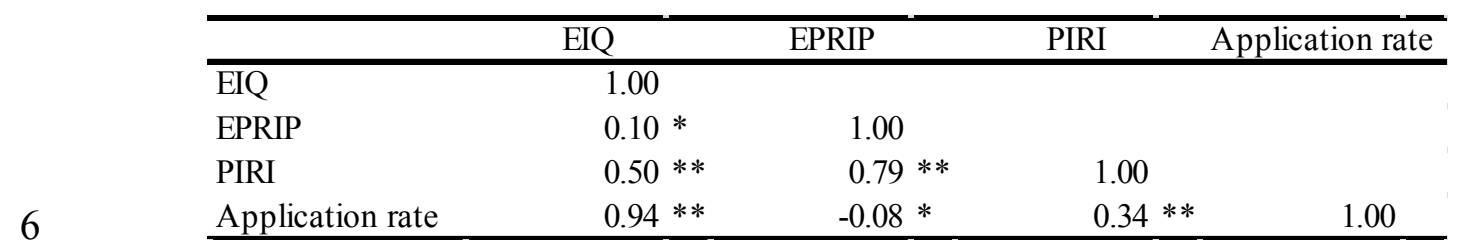

7

\subsubsection{User friendliness}

9Data for calculating the majority of the indicators are easily available. Data availability in this 10analysis does not concern data about the pesticides used by farmers, which are assumed to be 11 available and relatively easy to collect e.g. through a survey, but instead other inputs such as 12 parameters related to their physical and chemical properties, or toxicity.

13Data for some pesticides are missing in the indicators' internal databases, and in this study 14were substituted with the values (for EIQ and PestScreen) or property parameters (for 15POCER, EPRIP, and PIRI) of pesticide belonging to the same chemical classes. Regarding 16the health risk component of POCER, the low score in Table 6 depends on the actual, but 17probably temporary impossibility of accessing the EUROPOEM database, on which this 18indicator relies. The indicator proposed by Dosemeci et al. (2002) only requires information 19on pesticide use practices, although rather detailed, and not on pesticide properties.

20EIQ and PestScreen can be calculated without a highly specialist knowledge of pesticides and 21 have a simple calculation algorithm. POCER, in particular regarding the groundwater and 
1health modules, needs a higher level understanding of the model used and tends to require a 2significant amount of time for the calculations.

3All indicators except EIQ provide thresholds on which basis pesticide risk classes can be 4identified, but only EPRIP and PIRI provide such thresholds for both the risk associated with 5single pesticide applications and for the control strategies. However, PIRI is less transparent 6than EPRIP on the value at which such thresholds are set.

\subsubsection{Ability to represent the system}

8EIQ and PestScreen do not make use of site specific information, while POCER, EPRIP and 9PIRI do, thus providing a more appropriate representation of the specific system under 10analysis. The indicators also differ in terms of environmental compartments considered, and 11therefore on their ability to produce a comprehensive overview of risk in the environmental 12system, with PestScreen, POCER and EPRIP covering the most compartments. Concerning 13health risk, OHRI and the indicator proposed by Dosemeci et al. (2002) are limited to the 14occupational health of the farm worker.

\section{Discussion}

\subsection{Simple versus complex indicators}

18Comparison of the indicators with regard to the total environmental risk suggests that simple

19indicators not relying on an ETR approach cannot be used as a reliable proxy for more 20complex indicators, i.e. those relying on an ETR approach. In effect, the values of the former 21(i.e. EIQ, PestScreen) tended to correlate weakly with those of the latter (i.e. EPRIP, POCER 22and PIRI) when the total environmental risk was considered (Table 2). When single 23compartments were considered, the correlation between the indicator rankings was stronger, 24which confirms the results of other studies (Maud et al., 2001; Reus et al., 2002). However, 
1the correlations between non-ETR and ETR indicator values for single compartments were 2rather weak in the majority of cases (Tables 3 and 4 and supplementary material; Spearman 3 correlation test $<0.6$ ). This confirms the key role played by the calculation method, and in 4particular by the way the pesticide dose data are mathematically included in the formulas, and 5by the way compartment scores are aggregated into a total score, in determining the rankings.

6Moreover, for both the total environmental risk and the risk in selected compartments, the 7correlations among all indicators were weaker or not significant when the pest control strategy 8instead of the single applications was considered (Tables 2 to 4 and supplementary material). 9This underlines the importance of the aggregation procedure, i.e. from single pesticide 10applications to pest control strategy, adopted for the different indicators. For EIQ, PestScreen 11and POCER the individual values of each pesticide applications were summed up. In this 12 procedure, the number of treatments may have a greater impact on the final risk ranking than 13the impacts of single pesticides, because less and more risky pesticides are equally weighted. 14At the other extreme, EPRIP is the only indicator among those analysed in this study, which i) 15 gives more weight when high risk occurs in an environmental compartment, ii) relies on a 16probability function in order to account for a possible cumulative effect of exceeding two 17thresholds of risk, and iii) accounts for the degradation occurring between single pesticide 18applications. While some aspects of the aggregation procedure and scoring system are still 19undergoing validation (Balderacchi and Trevisan, 2010), these are clear strengths of EPRIP in 20comparison with other indicators.

21As also found by Maud et al. (2001), simple indicators tended to be driven by the application 22rate, which instead was less dominant in determining the values of ETR indicators, since these 23accord more weight to pesticide properties and environmental conditions such as distance to 24water body or slope. This difference between the two types of indicators was also tested by 25 calculating ETR indicators using average values for the site specific parameters (not shown in 
1the present paper). This significantly improved the correlations, proving the essential 2difference marked by using site specific parameters, and also confirmed the good correlation 3between PestScreen and EPRIP found by Juraske et al. (2007) using constant site specific data 4for EPRIP.

5An additional contribution to the difference in risk rankings between non-ETR and ETR 6indicators might come from the fact that EIQ and PestScreen adopt low ranges of values, 7which are likely to distort the differences in risk between pesticides with different properties, 8as pointed out by other studies (e.g. Dushoff et al., 1994).

9Finally, concerning the human health risk the results show a more complex picture, especially 10when the pest control strategy is considered. Correlations between rankings of different 11indicators, both ETR and non-ETR, tended to be weak and to change significantly when the 12 control strategies instead of the single applications were considered. These differences were 13very likely to depend not on the calculation procedure (ETR vs. non-ETR), but on the 14radically different attribution of risk potential to different factors in the indicators, i.e. misuse 15of protective equipment and highly toxic pesticides in POCER, powder formulations and large 16plot areas in OHRI, misuse of personal protective equipment and hygiene habits in Dosemeci 17et al (2002). Since no other similar comparison of health pesticide risk indicators exists in the 18literature, it was not possible to compare these results with those of other studies. Further 19research in this direction is recommended.

\subsection{Use of risk indicators in developing countries}

22LDCs are often characterized by particularly serious pesticide-related externalities but also by 23a general lack of resources, i.e. data, and expertise dedicated to environmental (Zhen and 24Routray, 2003; UNESCO, 2009) and health protection (Feola, 2010b), and the promotion of 
1sustainable agricultural production. In this context, the availability of a simple but reliable 2 pesticide risk indicator would be particularly relevant.

3 With regard to total environmental risk, the result seems to exclude the possibility of using 4simple, i.e. non-ETR, indicators as proxies for more complex, i.e. ETR, indicators in the 5assessment of farm-level pesticide-related risk (see also section 4.1). However, recent 6developments of EPRIP (Trevisan et al., 2009), and in particular the provision of a freely 7accessible user-friendly software with an internal database, have reduced the complexity of 8this indicator and made its use relatively simple, even with a data requirement comparable to 9that of EIQ and PestScreen (Table 6). Moreover, EPRIP is also the indicator that more strictly 10complies with the other requirements identified by previous studies for the development of 11 more accurate pesticide risk indicators (i.e. Levitan, 1997 and 2000; Maud et al., 2001; Reus 12et al., 2002). Nevertheless, non-ETR indicators remain very useful and accessible tools for 13discriminating between different potentially risky pesticides prior to application. In this 14regard, PestScreen is probably to be preferred to EIQ for it not only includes half life values 15 for single media but makes use of the overall environmental persistence.

16Concerning risk in single environmental compartments, the use of single components of 17different indicators might be considered. For example, PIRI proposes a convincing calculation 18approach for risk to surface water organisms, with the inclusion of the main transport routes, 19and accounting for possible site specific mitigation measures, which can be useful for 20monitoring purposes. The choice of the indicator to be used for a single environmental 21 compartment is likely to depend on the specific research, management or policy needs, on the 22availability of data and other necessary resources, and on an accurate analysis of the 23 characteristics of the different indicators.

24With regard to human health risk indicators, the results do not give strong support for one 25 specific indicator among those analysed. Because uncertainties still exist in the literature on 
1human exposure to pesticide during pesticide application and other operations, it might be 2preferable to avoid using indicators based on exposure models. In addition, these models are 3usually developed under European conditions, while it has been shown that in developing 4countries such as the study area, pesticide application techniques and chemicals used might 5differ extensively from those conditions (Feola and Binder 2010a and 2010b). In fact, 6following Blanco et al. (2005), it might be less important to accurately quantify the exposure 7of farmers to pesticides than to understand the determinants of exposure, both in terms of risk 8factors (e.g. misuse of personal protective equipment, hygiene habits) and of determinants of 9risky behaviour (e.g. cost of protective equipment, social norm) (Feola and Binder, 2010a). 10Consequently, algorithms such as the OHRI or the indicator proposed by Dosemeci et al. 11(2002) would seem more appropriate in assessing human health risk in developing countries 12than POCER. They provide a simple algorithm with limited data requirements and can 13support the identification of the most risky practices in pesticide handling and application. 14However, these indicators might also suffer from a bias towards North American or European 15application techniques, since in OHRI parameter values are partly drawn from UKPOEM 16(UKPOEM, 1992) and in Dosemeci et al. (2002) are mainly drawn from studies in North 17America and Europe. Further research on the validation of such parameter values in these 18algorithms under the pesticide application conditions found in many developing countries is 19needed.

\section{Summary of conclusions}

22This study investigated the appropriateness of seven pesticide risk indicators for use at farm 23level in Less Developed Countries, with particular reference to smallholding agriculture in the 24Colombian Andean region. The comparison of the indicators with regard to the total 25environmental risk suggests that simple indicators not relying on an exposure-toxicity ratio 
1approach cannot be used as reliable proxies for more complex ones, i.e. indicators based on an 2exposure-toxicity ratio approach. The choice of the indicator to be used for a single 3environmental compartment is likely to depend on specific research, management or policy 4needs, on the availability of data and other necessary resources, and on an accurate analysis of 5the characteristics of the various indicators. ETR indicators, such as EPRIP show a 6comparative advantage over non-ETR in best combining the need for a relatively simple tool 7to be used in contexts of limited data availability and resources, such as those usually 8characterizing Less Developed Countries, and that of a reliable estimation of environmental 9risk. Indicators not based on an exposure-toxicity ratio approach such as PestScreen remain 10useful and accessible tools for discriminating between different pesticides prior to application. 11Concerning the human health risk, simple algorithms such as the OHRI or that proposed by 12Dosemeci et al. (2002) seem more appropriate than complex ones in assessing human health 13risk in Less Developed Countries. This study also pointed out the need for further research on 14health risk indicators and their validation under the conditions encountered in Less Developed 15 Countries.

16

\section{Acknowledgments}

18The authors thank the University of Boyacá for providing the meteorological data and Camilo 19Lesmes for his comments on a previous version of this manuscript. The research was funded 20by the Swiss National Science Foundation.

\section{References}

23 Balderacchi, M., Trevisan, M., 2010. Comments on pesticide risl assessment by the revision of Directive EU 2491/414. Environ. Sci. Pollut. Res. 17, 523-528 
1 Bergkvist, P., 2004. Pesticide Risk Indicators at National Level and farm Level. A Swedish Approach. Swedish 2Chemical Inspectorate Sunbyberg, Sweden.

3 Binder, C.R., Patzel, N., 2001. Preserving tropical soil organic matter at watershed level. A possible 4contribution of urban organic waste. Nutr. Cycl. Agroecosys. 61, 171-181.

5 Binder, C.R., Feola, G., Julia K. Steinberger, J.K., 2010. Considering the normative, systemic and procedural 6dimensions in indicator-based sustainability assessments in agriculture, Environ. Impact Asses. Rev. 30(2), 71781.

8 Blanco, L., Aragón, A., Lundberg, I., Lidén, C., Wesseling, C., Nise, G., 2005. Determinants of dermal 9exposure among Nicaraguan subsistence farmers during pesticide applications with backpack sprayers. Ann. 10Occup. Hyg. 49, 17-24.

11 Cardenas, O., Silva, E., Morales, L., Ortiz, J., 2005. Estudio epidemiológico de exposición a plaguicidas 12 organofosforados y carbamatos en siete departamentos colombianos, 1998-2001. Biomedica 25, 170-180.

13 Castoldi, N., Finizio, A., Bechini, L., 2007. Agro-ecological indicators of field-farming system sustainability. 14II. Nutrients and pesticides. It. J. Agrometeorol. 1, 6-23.

15 CEC (Commission of the European Communities). Directions towards sustainable agriculture. Communication 16 from the Commission. Brussels; 1999.

17 Dosemeci, M., Alavanja, M.C.R., Rowland. A,S,, Mage, D., Hoar Zahm, S., Rothman, N., Lubin, J.H., Hoppin, 18J.A., Sandler, D.P., Blair, A., 2002. A Quantitative Approach to Estimating Exposure to Pesticides in the 19Agricultural Health Study. Ann. Occup. Hyg. 46(2), 245-260.

20 Dushoff, J., Caldwell, B., Mohler, C.L., 1994. Evaluating the Environmental Effect of Pesticides: A Critique of 21 the Environmental Impact Quotient. Am. Entomol. 40(3), 180-184.

22 Ecobichon, D.J., 2001. Pesticide use in developing countries. Toxicology 160, 27-33.

23 Falconer, K.,2002. Pesticide environmental indicators and environmental policy. J. Environ. Manage. 65, 28524300.

25 Feola, G., 2010a. Sustainability transition of pesticide use practices: behavioural dynamics and policy options. 26Doctoral thesis, Faculty of Science, University of Zurich.

27 Feola, G., 2010b. Agrochemicals put the health of rural workers and of the general population at risk. 28Salud(i)Ciencia 17(6), 560-562. 
1 Feola, G., Binder, C.R., 2010a. Why don't pesticide applicators protect themselves? Exploring the use of 2Personal Protective Equipment among Colombian smallholders. Int. J. Occup. Env. Heal. 16, 11-23.

3 Feola, G., Binder, C.R., 2010b. Identifying and investigating pesticide application types to promote a more 4sustainable pesticide use. The case of smallholders in Boyacá, Colombia. Crop Protect. 29, 612-622.

5 Feola, G., Binder, C.R., 2010c. Towards and improved understanding of farmers' behaviour: the integrative 6agent-centred (IAC) framework. Ecol. Econ. 69(12), 2323-2333.

7 Finizio, A., Villa, S., 2002. Environmental risk assessment for pesticides. A tool for decision making. Environ. 8Impact Assess. Rev. 22, 235-248.

9 Greitens, T.J., Day, E., 2007. An alternative way to evaluate the environmental effects of integrated pest 10management: Pesticide risk indicators. Renew. Agr. Food Syst. 22, 213-222.

11 Juraske, R., Antón, A., Castells, F., Huijbregts, M.A.J., 2007. PestScreen: A screening approach for scoring 12 and ranking pesticides by their environmental and toxicological concern. Environ. Int. 33, 886-893.

13 Juraske, R., Mosquera Vivas, C.S., Velasquez A.E., Garcia Santos, G., Berdugo Moreno, M.B., Diaz Gomez, 14J., Binder, C.R., Hellweg, S., Guerrero Dallos, J.A., 2011. Pesticide Uptake in Potatoes: Model and Field 15Experiments. Env. Sc. Tech. 45(2), 651-657.

16 Kookana, R., Correll, R., Miller, R., 2005. Pesticide impact rating index - a pesticide risk indicator for water 17quality. Water, Air, and Soil Pollution: Focus 5, 45-65.

18 Kookana, R.S., Kumar, A., Oliver, D., Correll, R., 2007. Pesticide Risk Indicators - Their Role in Minimising 19Off-Site Impacts of Pesticides on Water Quality, in: Kennedy, I.R., Solomon, K.R., Gee, S.J., Crossan, A.N. 20Wang, S., Sánchez-Bayo, F. (Eds.), Rational Environmental Management of Agrochemicals, American 21Chemical Society Symposium Series 966, pp. 37-52.

22 Kovach, J., Petzoldt, C., Degnil, J., Tette, J., 1992. A method to measure the environmental impact of 23pesticides. New York's Food and Life Sciences Bulletin 139, 1-8.

24 Leuenberger, M., 2005. Environmental and Health Risk Assessment of Cultivation Strategies in Tunja, 25Colombia. Diploma Thesis. Natural and Social Sciences Interface, ETH Zurich, Switzerland.

26 Levitan, L., 1997. An overview of pesticide impact and risk assessment systems. In: OECD, Workshop on 27Pesticide Risk Indicators, Copenhagen, April 21-23, 1997. 
1 Levitan, L., 2000. „How to“ and „why“: assessing the enviro-social impacts of pesticides. Crop Protect. 19, 2629-636.

3 Matthews, G.A., 2008. Attitudes and behaviours regarding use of crop protection products-A survey of more 4than 8500 smallholders in 26 countries. Crop Prot. 27, 834-846.

5 Ministerio de Agricultura y Desarrollo Rural (MADR), 2004. Acuerdo de competitividad de la cadena 6agroalimentaria de la papa, para el Departamento de Boyacá, 2004. Technical report, Ministerio de Agricultura y 7Desarrollo Rural, Bogotá, Colombia.

8 Ministerio de Agricultura y Desarrollo Rural (MADR), 2006. La cadena de la papa en Colombia. Una mirada 9global de su estructura y dinamica 1991-2005. Technical report, Ministerio de Agricultura y Desarrollo Rural, 10Bogotá, Colombia.

11 Maud, J., Edwards-Jones, G., Quin, F., 2001. Comparative evaluation of pesticide risk indices for policy 12 development and assessment in the United Kingdom. Agr. Ecosyst. Environ. 86, 59-73.

13 Muhammetoglu, A., Uslu, B., 2007. Application of environmental impact quotient model to Kumluca region, 14Turkey to determine environmental impacts of pesticides. Water Sci. Technol. 56(1), 139-145.

15 OECD (Organization for Economic Cooperation and Development). Environmental indicators for agriculture. 16Issues and Design. Paris: OECD Publication Service; 1999.

17 OECD (Organization for Economic Cooperation and Development). Environmental indicators for agriculture.18Methods and Results. Paris: OECDPublication Service; 2001

19 Ospina, J.M., Manrique, F.G., Ariza, N.E., 2008. Salud, ambiente y trabajo en poblaciones vulnerables: los 20cultivadores de papa en el centro de Boyacá. Revista de la Facultad Nacional de Salud Publica 26(2), $143-152$.

21 Padovani, L., Trevisan, M., Capri, E., 2004. A calculation procedure to assess potential environmental risk of 22pesticides at the farm level. Ecol. Indic. 4, 111-123.

23 PPDB, 2009. The Pesticide Properties Database. Database collated by the University of Hertfordshire as part of 24the EU-funded FOOTPRINT project (FP6-SSP-022704). FOOTPRINT. http://www.eu-footprint.org/ppdb.html. 25 Accessed: 9/13/2009.

26 Pimentel, D., Acquay, H., Biltonen, M., Rice, P., Silva, M., Nelson, J., Lipner, V., Giordano, S., Horowitz, A., 27D'Amore, M., 1992. Environmental and Economics Costs of Pesticide Use. BioScience 42(10), 750-760. 
1 Pradel, W., Forbes, G.A., Ortiz, O., Cole, D., Wanigaratne, S., Maldonado, L., 2009. Use of the environmental 2 impact quotient to estimate empacts of pesticide usage in three Peruvian potato production areas. Working Paper 3No. 2009-2, Integrated Crop Management Division, International Potato Center, Lima, Peru.

4 Reus, J., Leendertse, P., Bockstaller, C., Fomsgaard, I., Gutsche, V., Lewis, K., Nilsson, C., Pussemier, L., 5Trevisan, M., van der Werf, H., Alfarrova, F., Blümel, S., Isart, J., McGrath, D., Seppälä, T., 2002. Comparison 6 and evaluation of eight pesticide environmental risk indicators developed in Europe and recommendations for 7 future use. Agr. Ecosyst. Environ. 90, 177-187.

8 Schoell, R., Binder C.R., 2009. System Perspectives of Experts and Farmers Regarding the Role of Livelihood 9Assets in Risk Perception: Results from the Structured Mental Model Approach. Risk Anal. 29(2), 205-222.

10 Stenrod, M., Heggen, H.E., Bolli, R.I., Eklo, O.M., 2008. Testing and comparison of three pesticide risk 11 indicator models under Norwegian conditions-A case study in the Skuterud and Heiabekken catchments. Agr. 12Ecosyst. Environ. 123, 15-29.

13 Trevisan, M., Di Guardo, A., Balderacchi, M., 2009. An environmental indicator to drive sustainable pest 14management practices. Environ. Modell. Softw. 24, 994-1002.

15 UKPOEM, 1992. United Kingdom predictive operator exposure model - A users guide. Technical report, 16Pesticide Safety Directorate, UK.

17 UNESCO (United Nations Educational, Scientific and Cultural Organization), 2009. Mapping research systems 18 in developing countries. Synthesis report.

19 Van der Werf, H., 1996. Assessing the impact of pesticides on the environment. Agr. Ecosyst. Environ. 60, 812096.

21 Vercruysse, F., Steurbaut, W., 2002. POCER, the pesticide occupational and environmental risk indicator. Crop 22Protect. 21, 307-315.

23 Zhen, L., Routray, J.K., 2003. Operational indicators for Measuring Agricultural Sustainability in Developing 24Countries. Environ. Manag. 32(1), 34-46. 


\title{
1Suitability of pesticide risk indicators for Less Developed Countries: A 2comparison
}

\author{
3Feola, G. ${ }^{1,2 *}$, Rahn, E. ${ }^{1,3}$, Binder, C.R. ${ }^{1,4}$ \\ $4^{1}$ Department of Geography, University of Zurich, Winterthurerstrasse 190, 8057 Zurich, Switzerland \\ $5^{2}$ Potsdam Institute for Climate Impact Research, Telegraphenberg A62, 14473 Potsdam, Germany \\ $6^{3}$ Federal Office for Spatial Development, Mühlestrasse 2, CH-3063 Ittigen, Switzerland \\ $7^{4}$ Institute for System Science, Innovation and Sustainability Research, University of Graz, Merangasse 18/I, \\ 88010 Graz, Austria \\ 9* Corresponding author: feola.giuseppe@googlemail.com
}

10

11

12

Supplementary data

13

14

\section{$15 \mathrm{~A}$ - Short description of the indicators}

16

\section{EIQ}

18The Environmental Impact Quotient (EIQ) (Kovach et al., 1992) estimates the environmental $19 \mathrm{impact}$ of a pesticide by aggregating the hazard posed to farm workers, consumers and the 20local environment in one score. Each of these three components in the equation is given equal 21 weight, but within each component, factors are given a different weighting $(1,3$ or 5$)$ in order 22to represent their importance. Similarly, toxicological data, which are drawn from different 23 sources and databases, are normalized into a three level scale depending on their danger, i.e. 1 24 for low, 3 for medium and 5 for high toxicity.

25

$$
\begin{aligned}
& \mathrm{EIQ}=\{\mathrm{C}[(\mathrm{DT} \times 5)+(\mathrm{DT} \times \mathrm{P})]+[(\mathrm{C} \times((\mathrm{S}+\mathrm{P}) / 2) \times \mathrm{SY})+\mathrm{L}]+[(\mathrm{F} \times \mathrm{R})+(\mathrm{D} \times \\
& ((\mathrm{S}+\mathrm{P}) / 2) \times 3)+(\mathrm{Z} \times \mathrm{P} \times 3)+(\mathrm{B} \times \mathrm{P} \times 5)]\} / 3
\end{aligned}
$$

29

30Where: $\mathrm{DT}=$ dermal toxicity; $\mathrm{C}=$ chronic toxicity; $\mathrm{SY}=$ systemicity; $\mathrm{F}=$ fish toxicity; $\mathrm{L}=$ 31leaching potential; $\mathrm{R}=$ surface loss potential; $\mathrm{D}=$ bird toxicity; $\mathrm{S}=$ soil half-life; $\mathrm{Z}=$ bee 32toxicity; $\mathrm{B}=$ beneficial arthropod toxicity; $\mathrm{P}=$ plant surface half-life.

33An EIQ field use rating (FUR) allows the EIQ to be calculated for pest control strategies 34(equation 2).

35

36 EIQ $($ FUR $)=$ EIQ $\times(\%$ active ingredient $) \times$ rate

\section{PestScreen}


1PestScreen was developed as a screening tool to provide a relative assessment of pesticide 2 hazards to human health and the environment (Juraske et al., 2007). The indicator provides a 3ranking approach, which not only includes data on toxic effects and bioaccumulation, but also 4on persistence and mobility of pesticides in the environmental compartments. The indicator 5 provides a simple categorical distinction between pesticides as a function of application dose, 6and three hazard categories, i.e. fate, exposure and toxicity.

7

$8 \quad$ PestScore $=\mathrm{D}^{*}\left[\left(\sum \mathrm{F}_{\mathrm{i}=2} / 2\right)+\mathrm{E}_{\mathrm{i}=1}+\left(\sum \mathrm{T}_{\mathrm{i}=4} / 4\right)\right]$

9

10Where: $\mathrm{D}=$ application dose; $\sum \mathrm{F}_{\mathrm{i}=2}$ is the sum of overall persistence and long-range transport 11 potential; $\mathrm{E}$ is the intake fraction; $\sum \mathrm{T}_{\mathrm{i}=4}$ is the sum of toxicity for rats, bees, fish and humans.

12Each hazard category is given the same weight, and is scored on a 1 to 4 scale, i.e, low to very 13high concern. The hazard category's sub-scores are calculated using physical and chemical 14properties and cut-off criteria.

15

\section{POCER}

17The pesticide occupational and environmental risk indicator (POCER) was developed by 18 Vercruysse and Steurbaut (2002). It consists of ten modules covering both human health and 19environmental risk, which are based on the modules of Directive 91/414/EC (CEC, 1994) for 20the evaluation and acceptance of plant protection products in the European Union. A risk 21 index is calculated for each module as the quotient of the estimated human exposure of the 22predicted environmental concentration and a toxicological reference value. The latter are 23endpoints defined by the Annex VI of the Directive 91/414/EC (CEC, 1994). For example, the 24risk index for the worker is calculated as

$$
\mathrm{RI}_{\text {worker }}=\mathrm{DE} \times \mathrm{Ab}_{\mathrm{DE}} / \mathrm{AOEL}
$$

27

28Where $\mathrm{DE}$ is the dermal exposure ( $\mathrm{mg} /$ person/day), $\mathrm{Ab} \mathrm{b}_{\mathrm{DE}}$ is the dermal absorption factor 29(fraction), and the AOEL is the Acceptable Operator Exposure Limit (mg/kg body 30weight/day).

31 The ten risk indices are aggregated into a total risk indicator by transforming each index into a 32 value ranging from 0 to 1 . In order to do that, a lower and an upper limit have to be 33 established for the ten risk indices. The risk of a pesticide to the different components 34depends on the extent to which the lower limit is exceeded. Finally, the total risk of a 35 pesticide is calculated by summing the values of the ten components (i.e. assuming equal 36weight).

\section{7}

\section{EPRIP}

41The Environmental Potential Risk Indicator for Pesticide (EPRIP) was first developed by 42Padovani et al. (2004) and then updated by Trevisan et al. (2009) to improve the indicator, 
1and in particular its applicability to different weather conditions. EPRIP is based on an ETR 2approach, by using the predicted environmental concentration estimated at local scale divided 3 by short-term toxicological parameters (i.e. $\mathrm{LD}_{50}$, NOEL). The ETR values are then 4normalized into risk points (RP) using a scale ranging from 1 to 5 , where 1 represents no risk 5 and 5 represents very large risk. Finally, to obtain the overall EPRIP score, the RP values for 6the different compartments are multiplied as follows:

7

$8 \quad E P R I P=R_{\text {gw }} \times R_{\text {sw }} \times R P_{s} \times R_{a}+25 \times N 4+50 \times N 5$

9

10 Where $\mathrm{RP}_{\mathrm{gw}}$ is the risk point for groundwater, $\mathrm{RP}_{\mathrm{sw}}$ is the highest risk point among six different 11 values for surface water, $\mathrm{RP}_{\mathrm{s}}$ is the risk point for soil, $\mathrm{RP}_{\mathrm{a}}$ is the risk point for air, $\mathrm{N} 4$ is the 12 number of RP values equal to 4 and N5 is the number of RP values equal to 5 .

13

\section{PIRI}

15The Pesticide Impact Rating Index (PIRI) (Kookana et al., 2005) assesses the off-site 16migration potential of pesticides and risk of surface and groundwater contamination. PIRI 17makes use of an exposure-toxicity ratio approach and is based on an ad hoc developed 18software package. The risk assessment is based on pesticide use; the pathway through which 19the pesticides are released to the water resources (drift, runoff, erosion, leaching) and the 20value of the water resources threatened. Each component is quantified using pesticide 21characteristics (e.g. toxicity to organisms at different trophic levels, i.e. fish, daphnia, algae), 22 environmental and site conditions (e.g. organic carbon content of soil, water input, slope of 23land, soil loss, recharge rate, depth of water table).

24

\section{OHRI}

26The Operator Health Risk Indicator (OHRI) (Bergkvist, 2004) provides a measure of risk to 27 the pesticide operator. It combines data on hazard and exposure and combines them with data 28 on intensity of pesticide use. The toxicity values were drawn from the EU risk phrases defined 29in Annex II of the EU Directive 67/548/EEC as amended by the EU Directive 2001/59/EC 30 and scored by the authors. The protective factors of different pieces of personal protective 31 equipment, used to calculate the indicator's value, are drawn mainly from the UKPOEM 32(1992).

36Where: $\mathrm{AT}=$ area treated; OT = operator toxicity; $\mathrm{FT}=$ formulation type; $\mathrm{AMO}=$ application 37 method; $\mathrm{PMO}=$ use of personal protective equipment.

39Dosemeci et al. (2002)

40Dosemeci et al. (2002) developed a quantitative method for estimating the intensity of 41 exposure to pesticides in the agricultural sector. The algorithms developed, i.e. a detailed and 42a general one, consider different factors which contribute to the exposure of the operator to 
1pesticides. The exposure scores assigned to each factor are mainly derived from empirical 2 studies in the scientific literature.

3

4 Intensity level $=[($ Mix x Enclosed $)+($ Appl $\mathrm{x}$ Cab $)+$ Repair + Wash $] \mathrm{x} P P E \mathrm{x}$

5 Repl x Hyg x Spill

7Where: Mix is a score for the method of pesticide mixing; Enclosed is a score for whether or 8 not an enclosed mixing system is used; $\mathrm{Appl}$ is a score related to the application method; $\mathrm{Cab}$ 9refers to whether or not a tractor with enclosed cab and/or charcoal filter is used; Repair is a 10score for the status of maintenance of the equipment; Wash is a score for the practice of 11 washing the equipment after pesticide application; Repl is a score for the rate of replacement 12of old protective gloves; Hyg is a score for the practices of personal hygiene; Spill is a score 13 for whether or not clothes are changed after a spill.

14

15 


\section{B- Overview of data requirements}

\begin{tabular}{|c|c|c|c|c|c|c|c|}
\hline \multirow{3}{*}{ Data } & \multicolumn{7}{|c|}{ Indicators* } \\
\hline & & Pest & & & & & $\begin{array}{l}\text { Dosemeci } \\
\text { et al. }\end{array}$ \\
\hline & EIQ & Screen & POCER & EPRIP & PIRI & OHRI & \\
\hline \multicolumn{8}{|l|}{ PESTICIDE APPLICATION } \\
\hline Application method & & & * & & & * & * \\
\hline Application rate & * & * & * & * & * & & \\
\hline Duration of re-entry & & & * & & & & \\
\hline Exposure area for bystanders & & & * & & & & \\
\hline Frequency of application & * & * & * & * & * & & \\
\hline Inhalation exposure for the applicator & & & * & & & & \\
\hline $\begin{array}{l}\text { Minimum number of days from application of } \\
\text { pesticides to first rainfall/irrigation }\end{array}$ & & & & & * & & \\
\hline Parcel area & & & * & * & * & * & \\
\hline Parcel perimeter & & & & $*$ & & & \\
\hline $\begin{array}{l}\text { Safety practices (washing, changing clothes, } \\
\text { etc.) }\end{array}$ & & & & & & & $*$ \\
\hline Use of personal protective equipment & & & * & & & * & $*$ \\
\hline Transfer factor for re-entry & & & * & & & & \\
\hline Width of buffer zone & & & & & * & & \\
\hline Work rate (ha/h) & & & * & & & & \\
\hline \multicolumn{8}{|l|}{ PESTICIDE PROPERTIES } \\
\hline Henry constant & & & & * & & & \\
\hline $\mathrm{k}_{\mathrm{oc}}$ & & & & $*$ & * & & \\
\hline Long range transport potential & & * & & & & & \\
\hline Mode of action & * & & & & & & \\
\hline Molecular weight & & & & * & & & \\
\hline Overall persistence & & * & & & & & \\
\hline Pesticide composition (active ingredients) & * & * & * & * & * & & \\
\hline Pesticide formulation (liquid/powder) & & & * & & & * & \\
\hline Pesticide half-life in soil & * & & * & * & * & & \\
\hline Pesticide solubility in water & & & & * & & & \\
\hline Plant surface residue half-life & * & & & & & & \\
\hline Vapour pressure & & & & * & & & \\
\hline TOXICITY & & & & & & & \\
\hline Acceptable daily intake (ADI) & & * & & & & & \\
\hline Acceptable operator exposure limit (AOEL) & & & $*$ & & & & \\
\hline $\mathrm{EC}_{50}$ algae & & & $*$ & $*$ & $*$ & & \\
\hline $\mathrm{EC}_{50}$ daphnia & & & $*$ & * & $*$ & & \\
\hline $\mathrm{LC}_{50}$ earthworms & & & * & * & & & \\
\hline $\mathrm{LC}_{50}$ fish & $*$ & $*$ & * & * & $*$ & & \\
\hline $\mathrm{LC}_{50}$ rabbit/rat & * & & & & & & \\
\hline $\mathrm{LD}_{50}$ bees & & $*$ & * & & & & \\
\hline $\mathrm{LD}_{50}$ birds & & & * & & & & \\
\hline $\mathrm{LD}_{50}$ rat & & * & & * & & & \\
\hline Long-term health effects & * & & & & & & \\
\hline Operator toxicity & & & & & & * & \\
\hline Toxicity to bees & * & & & & & & \\
\hline Toxicity to beneficial arthropods & $*$ & & * & & & & \\
\hline Toxicity to birds & * & & & & & & \\
\hline
\end{tabular}




\begin{tabular}{|c|c|c|c|c|c|c|c|}
\hline \multirow[b]{2}{*}{ Data } & \multicolumn{7}{|c|}{ Indicators* } \\
\hline & FIO & PestScre & POCFR & FPRIP & PIRI & OHRI & $\begin{array}{l}\text { Dosemeci } \\
\text { et al. }\end{array}$ \\
\hline \multicolumn{8}{|l|}{ SOIL } \\
\hline Bulk density of soil & & & * & $*$ & & & \\
\hline \multicolumn{8}{|l|}{$\begin{array}{l}\text { Estimated average soil loss during period of } \\
\text { interest }\end{array}$} \\
\hline Slope of land to water body & & & & $*$ & $*$ & & \\
\hline Soil depth & & & * & & & & \\
\hline Soil moisture & & & & & $*$ & & \\
\hline Soil organic carbon content & & & & $*$ & $*$ & & \\
\hline Soil type & & & & $*$ & * & & \\
\hline \multicolumn{8}{|l|}{ WATER BODIES } \\
\hline Annual recharge rate & & & & $*$ & & & \\
\hline Depth of nearest water body & & & * & $*$ & & & \\
\hline Depth of water table & & & & $*$ & $*$ & & \\
\hline Diameter of nearest water body & & & & & $*$ & & \\
\hline Distance from edge of crop to water body & & & & $*$ & * & & \\
\hline Groundwater and runoff potential & $*$ & & & & & & \\
\hline Recharge rate during period of interest & & & & & * & & \\
\hline Water table thickness & & & & $*$ & & & \\
\hline Width of nearest water body & & & * & $*$ & & & \\
\hline \multicolumn{8}{|l|}{ METEOROLOGICAL CONDITIONS } \\
\hline $\begin{array}{l}\text { Average maximum air temperature during } \\
\text { period of interest }\end{array}$ & & & & & $*$ & & \\
\hline Maximum daily rain & & & & $*$ & & & \\
\hline Mean annual precipitation & & & & $*$ & & & \\
\hline Mean annual temperature & & & & $*$ & & & \\
\hline Total rainfall during period of interest & & & & & $*$ & & \\
\hline \multicolumn{8}{|l|}{ OTHER DATA } \\
\hline Body weight of birds & & & $*$ & & & & \\
\hline Body weight of bystanders & & & $*$ & & & & \\
\hline Crop interception factor & & & $*$ & $*$ & & & \\
\hline Daily food intake by birds & & & * & & & & \\
\hline Dermal absorption factor & & & $*$ & & & & \\
\hline Drift & & & $*$ & & & & \\
\hline Drinking water standard & & & & * & & & \\
\hline Intake fraction & & $*$ & & & & & \\
\hline Leaf area index & & & $*$ & & & & \\
\hline Total irrigation during period of interest & & & & & $*$ & & \\
\hline
\end{tabular}

$3 *$ An asterisk indicates that the data was used in calculating the respective indicator.

4

5The specific values used to calculate the indicators, as well as sources and assumptions made, 6are to be found in Rahn, E., 2010. Environmental and health risk indicators to assess pesticide 7use. A comparison of different indicators for the case of potato production in La Hoya, 8Colombia. Master thesis, Department of Geography, University of Zurich, Switzerland. 


\section{C - Criteria for the comparison based on key indicator characteristics}

2Table 8. Criteria for the comparison based on key indicator characteristics and corresponding scores.

\begin{tabular}{|c|c|c|c|c|}
\hline & Scores & $*$ & $* *$ & $* * *$ \\
\hline \multirow[t]{3}{*}{$\begin{array}{l}\text { User } \\
\text { friendliness }\end{array}$} & Data availability & $\begin{array}{l}\text { Not available } \\
\text { (additional } \\
\text { as sumptions needed) }\end{array}$ & $\begin{array}{l}\text { Available for some } \\
\text { pesticides }\end{array}$ & Easily available \\
\hline & $\begin{array}{l}\text { Calculation } \\
\text { procedure }\end{array}$ & $\begin{array}{l}\text { Calculation procedure } \\
\text { knowledge-intensive } \\
\text { and time-consuming }\end{array}$ & $\begin{array}{l}\text { Calculation procedure } \\
\text { either knowledge } \\
\text { intensive or time- } \\
\text { consuming }\end{array}$ & $\begin{array}{l}\text { Calculation procedure } \\
\text { neither knowledge } \\
\text { intensive nor time- } \\
\text { consuming }\end{array}$ \\
\hline & Score interpretation & $\begin{array}{l}\text { Relative comparison } \\
\text { (ranking) }\end{array}$ & $\begin{array}{l}\text { Risk classes given } \\
\text { when single } \\
\text { applications are } \\
\text { considered }\end{array}$ & $\begin{array}{l}\text { Risk classes given } \\
\text { both when single } \\
\text { applications and } \\
\text { control strategy are } \\
\text { considered }\end{array}$ \\
\hline \multirow{3}{*}{$\begin{array}{l}\text { Ability to } \\
\text { represent } \\
\text { the specific } \\
\text { system } \\
\text { under study }\end{array}$} & Site specific data & $\begin{array}{l}\text { No site specific data } \\
\text { used }\end{array}$ & - & Site specific data used \\
\hline & $\begin{array}{l}\text { Compartments } \\
\text { considered } \\
\text { (environment) }\end{array}$ & $\begin{array}{l}\text { One-two } \\
\text { compartments }\end{array}$ & Three compartments & $\begin{array}{l}\text { Four-Five } \\
\text { compartments }\end{array}$ \\
\hline & $\begin{array}{l}\text { Compartments } \\
\text { considered (health) }\end{array}$ & One compartment & Two compartments & Three compartments \\
\hline
\end{tabular}

4

5

\section{D - Additional tables}

7Table 9. Correlation between rankings of the 581 pesticide applications for risk to soil (Spearman 8 correlation test)

\begin{tabular}{lccc}
\hline & EPRIP & POCER & Application rate \\
\hline EPRIP & 1.00 & & \\
POCER & $0.82 * *$ & 1.00 & \\
Application rate & 0.07 & $0.42 * *$ & 1.00 \\
\hline$* p>0.05 ; * * p>0.01$ & & &
\end{tabular}

$9 * \mathrm{p}>0.05 ; * * \mathrm{p}>0.01$

10

11Table 10. Correlation between rankings of the 72 control strategies for risk to soil (Spearman correlation 12test)

\begin{tabular}{lccc}
\hline & EPRIP & POCER & Application rate \\
\hline EPRIP & 1.00 & & \\
POCER & $0.38 * *$ & 1.00 & \\
Application rate & 0.14 & $0.32 * *$ & 1.00 \\
\hline
\end{tabular}

$13^{* \mathrm{p}>0.05 ; * * \mathrm{p}>0.01}$

14

15

16

17

18

19Table 11. Correlation between rankings of the 581 pesticide applications for risk to beneficial arthropods 20(Spearman correlation test) 


\begin{tabular}{lrrr}
\hline & EIQ & POCER & Application rate \\
\hline EIQ & 1.00 & & \\
POCER & $-0.50 * *$ & 1.00 & \\
Application rate & $0.98 * *$ & - & 1.00 \\
\hline
\end{tabular}

$1 * \mathrm{p}>0.05 ; * \mathrm{p}>0.01$

2

3Table 12. Correlation between rankings of the 72 control strategies for risk to beneficial arthropods 4(Spearman correlation test)

\begin{tabular}{lcrc}
\hline & EIQ & POCER & Application rate \\
\hline EIQ & 1,00 & & \\
POCER & 0,09 & 1,00 & \\
Application rate & $0,99 * *$ & 0,09 & 1,00 \\
\hline
\end{tabular}

$5^{* \mathrm{p}>0.05 ; * * \mathrm{p}>0.01}$

6

7Table 13. Correlation between rankings of the 581 pesticide applications for risk to birds (Spearman 8 correlation test)

\begin{tabular}{lccc}
\hline \multicolumn{2}{c}{ EIQ } & POCER & Application rate \\
\hline EIQ & 1.00 & & \\
POCER & $0.43 * *$ & 1.00 & \\
Application rate & $0.94 * *$ & $0.25 * *$ & 1.00 \\
\hline$* \mathrm{p}>0.05 ; * \mathrm{p}>0.01$ & & &
\end{tabular}

10

11Table 14. Correlation between rankings of the 72 control strategies for risk to birds (Spearman 12 correlation test)

\begin{tabular}{lccc}
\hline & EIQ & POCER & Application rate \\
\hline EIQ & 1.00 & & \\
POCER & $0.35 * *$ & 1.00 & \\
Application rate & $0.96 * *$ & $0.28 *$ & 1.00 \\
\hline
\end{tabular}

$13^{* \mathrm{p}>0.05 ; * * \mathrm{p}>0.01}$

14

15Table 15. Correlation between rankings of the 581 pesticide applications for risk to bees (Spearman 16correlation test)

\begin{tabular}{lccc}
\hline & EIQ & POCER & Application rate \\
\hline EIQ & 1.00 & & \\
POCER & 0.05 & 1.00 & \\
Application rate & $0.96 * *$ & $0.90 *$ & 1.00 \\
\hline
\end{tabular}

$17^{* \mathrm{p}>0.05 ; * * \mathrm{p}>0.01}$

18

19

20

21

22

23Table 16. Correlation between rankings of the 72 control strategies for risk to bees (Spearman correlation 24test) 


\begin{tabular}{lccc}
\hline & EIQ & POCER & Application rate \\
\hline EIQ & 1.00 & & \\
POCER & $0.43 * *$ & 1.00 & \\
Application rate & $0.97 * *$ & $0.34 * *$ & 1.00 \\
\hline
\end{tabular}

$1 * \mathrm{p}>0.05 ; * \mathrm{p}>0.01$

2

3Table 17. Correlation between rankings of the 581 pesticide applications for risk to farm worker 4(Spearman correlation test)

\begin{tabular}{lccc}
\hline & EIQ & POCER & Application rate \\
\hline EIQ & 1.00 & & \\
POCER & $0.56 * *$ & 1.00 & \\
Application rate & $0.91 * *$ & $0.51 * *$ & 1.00 \\
\hline
\end{tabular}

$5^{* \mathrm{p}>0.05 ; * * \mathrm{p}>0.01}$

6

7Table 18. Correlation between rankings of the 72 control strategies for risk to farm worker (Spearman 8 correlation test)

\begin{tabular}{lccc}
\hline & EIQ & POCER & Application rate \\
\hline EIQ & 1.00 & & \\
POCER & $0.49 * *$ & 1.00 & \\
Application rate & $0.97 * *$ & $0.46 * *$ & 1.00 \\
\hline
\end{tabular}

$9 * \mathrm{p}>0.05 ; * * \mathrm{p}>0.01$

10

11

12

13

14 